ISSN: 2578-0263

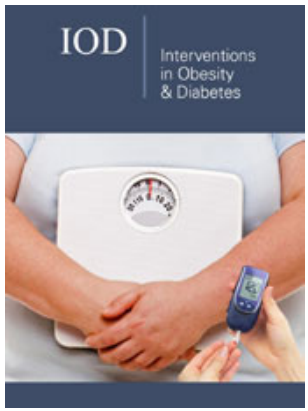

*Corresponding author: Shehab M Abd ElKader, Department of Physical Therapy, Faculty of Applied Medical Sciences, King Abdulaziz University, Jeddah,Saudi Arabia

Submission: 監January 11, 2021

Published: 阱January 28, 2021

Volume 4 - Issue 5

How to cite this article: Abd ElKader SM, AlSharif FM. Impact of Aerobic Versus Resistance Exercise Training on Glucose Control and Biomarkers of Oxidative Stress among Saudi Patients with Type 2 Diabetes. Interventions Obes Diabetes 4(5). IOD.000598. 2021

DOI: 10.31031/IOD.2021.04.000598

Copyright@ Shehab M Abd ElKader. This article is distributed under the terms of the Creative Commons Attribution 4.0 International License, which permits unrestricted use and redistribution provided that the original author and source are credited.

\section{Impact of Aerobic Versus Resistance Exercise Training on Glucose Control and Biomarkers of Oxidative Stress among Saudi Patients with Type 2} Diabetes

\author{
Abd ElKader SM ${ }^{1}$ and AlSharif FM ${ }^{2 *}$ \\ ${ }^{1}$ Department of Physical Therapy, Faculty of Applied Medical Sciences, King Abdulaziz University, Saudi \\ Arabia \\ ${ }^{2}$ Department of Medical Laboratory Technology, Faculty of Applied Medical Sciences, King Abdulaziz \\ University, Saudi Arabia
}

\section{Abstract}

Background: Oxidative stress is important in pathogenesis of diabetes complications. Limited research available regarding role of exercise in alleviation of oxidative stress in type 2 diabetes mellitus (T2DM).

Objective: The target of this study was compared response of insulin resistance and oxidative stress to aerobic versus resisted exercise training in T2DM patients.

Material and Methods: Eighty T2DM patients, the range of age ranged was 45 to 57 year and body mass index was 30 to $36 \mathrm{~kg} / \mathrm{m} 2$. Smoking, renal failure, heart failure, respiratory failure, hepatitis and pregnancy were the exclusion criteria. Participants randomly assigned equally into group (A) received aerobic treadmill exercise and group (B) received resistance exercise for 3 months.

Results: Following aerobic and resistance exercises, there was significant reduction in the mean values of Homeostasis Model Assessment-Insulin Resistance Index (HOMA-IR),conjugated dienes (CD) and malondialdehyde (MDA), in addition to significant elevation in the mean values of the quantitative insulin-sensitivity check index (QUICKI),glutathione peroxidase (GPX), superoxide dismutase (SOD) and glutathione (GSH). However, significant differences found between both groups after training.

Conclusion: Aerobic exercise is superior to resistance exercise in modulating insulin resistance and oxidative stress in type 2 diabetes patients.

Keywords: Aerobic exercise; Diabetes mellitus; Resisted exercises; Oxidative stress

Abbreviations: T2DM: Type 2 Diabetes Mellitus; QUICKI: Quantitative Insulin-Sensitivity Check Index; SOD: Superoxide Dismutase; HOMA-IR: Homeostasis Model Assessment-Insulin Resistance Index

\section{Introduction}

Diabetes mellitus is a worldwide medical problem affects about $6 \%$ world population which is expected to reach more than 550 million 2030 [1]. Many system dysfunctions are associated with diabetes include renal, cardiac, eye, nerve and blood vessels [2]. Hyperglycemia induces oxidative stress and inflammation [3]. Oxidative stress is usually associated with diabetes because of abnormal glucose control [4-7]. However; oxidative stress is one of the main cause of diabetic complications [8-11]. In the other hand, metabolic control enhance antioxidant defense system in type 2 diabetes patients (T2DM) [12]. Hyperglycemia seems to cause an imbalance between oxidant and antioxidant systems in T2DM patients [13]. Physical activity reduces rate of mortality and morbidity in diabetic individuals [14-16]. Therefore, regular exercise is an effective therapeutic strategy for T2DM [17]. Aerobic exercise improves metabolic control and reduces the cardiovascular disease risk [18]. Physical activity ameliorate insulin resistance and oxidative stress [19-23]. Limited studies available regarding the more appropriate exercise modulates the metabolic control and oxidative stress of T2DM patients, so that the target of present study was compare response of insulin resistance and oxidative stress to aerobic versus resisted exercise training in T2DM patients.. 


\section{Materials and Methods}

\section{Subjects}

Eighty T2DM patients, the mean of age ranged was $49.71- \pm 7.28$ year and body mass index was $32.87 \pm 4.12 \mathrm{~kg} / \mathrm{m}^{2}$. Smoking, renal failure, heart failure, respiratory failure, hepatitis and pregnancy were the exclusion criteria. Participants randomly assigned equally into group (A) received aerobic treadmill exercise and group (B) received resistance exercise for 3 months. Informed written consent was signed by all participants.

\section{Measurements}

Insulin and insulin resistance assessment: Serum insulin was measured using an insulin kit (Roche Diagnostics, Indianapolis, IN, USA) by a cobas immunoassay analyzer (Roche Diagnostics). However, formula used to assess insulin resistance was homeostasis model assessment (HOMA-IR). HOMA-IR=[fasting blood glucose (mmol/l)_fasting insulin (mIU/ml)]/22.5 [24]. While the formula used to assess insulin sensitivity was quantitative insulinsensitivity check index (QUICKI) with the formula: QUICKI=1/ [log(insulin)+log(glucose)] [25].

Oxidative stress markers and anti-oxidant status assessment: The method described by Esterbauer et al used to assess plasma level of malondialdehyde (MDA) [26]. While the method described by Weckbecker and Cory used to assess Glutathione (GSH) level [27]. In addition, the method described by Masnini used to measure glutathione peroxidase (GPx) and superoxide dismutase (SOD) [28].

\section{Procedures}

Group (A): received treadmill aerobic exercise (Enraf Nonium, Model display panel Standard, NR 1475.801, Holand) following American College of Sports Medicine recommendation [29]. Participants conducted training intensity of $60-80 \%$ of maximum heart rate for 30 minutes, 3 sessions/week.

Group (B): received resisted exercises using resistance gym machines (Nautilus Sports/Medical Industries, Independence, VA). Participants conducted training intensity of 60 and $80 \%$ of their one maximal repetition weight (1-RM) for 30 minutes, 3 sessions/ week [30].

\section{Results}

Participants' criteria before the study did not revealed significant differences between both groups as shown in Table 1. Following aerobic and resistance exercises, there was significant reduction in the mean values of Homeostasis Model AssessmentInsulin Resistance Index (HOMA-IR), conjugated dienes (CD) and malondialdehyde (MDA), in addition to significant elevation in the mean values of the quantitative insulin-sensitivity check index (QUICKI),glutathione peroxidase (GPX), superoxide dismutase (SOD) and glutathione (GSH) (Tables 2 \& 3). However, significant differences found between both groups after training (Table 4).

Table 1: Participants criteria before the study. BMI: Body Mass Index; SBP: Systolic Blood Pressure; DBP: Diastolic Blood Pressure; HDL-C: High-Density Lipoprotein Cholesterol; HBA1c: Glycosylated Hemoglobin.

\begin{tabular}{|c|c|c|c|}
\hline & Group (A) & Group (B) & Significance \\
\hline Age (year) & $48.92 \pm 7.15$ & $49.75 \pm 7.83$ & $\mathrm{P}<0.05$ \\
\hline Gender (male/female) & $26 / 14$ & $29 / 11$ & $\mathrm{P}<0.05$ \\
\hline BMI $\left(\mathrm{kg} / \mathrm{m}^{2}\right)$ & $32.84 \pm 5.14$ & $32.25 \pm 5.11$ & $\mathrm{P}<0.05$ \\
\hline Duration of diabetes (years) & $12.87 \pm 4.91$ & $12.56 \pm 4.62$ & $\mathrm{P}<0.05$ \\
\hline SBP (mmHg) & $145.16 \pm 11.18$ & $143.27 \pm 10.32$ & $\mathrm{P}<0.05$ \\
\hline DBP (mmHg) & $89.14 \pm 8.35$ & $86.92 \pm 8.64$ & $\mathrm{P}<0.05$ \\
\hline Total Cholesterol (mg/dL) & $205.37 \pm 18.42$ & $200.13 \pm 16.25$ & $\mathrm{P}<0.05$ \\
\hline HDL-C( mg/dL) & $41.63 \pm 6.81$ & $44.53 \pm 7.15$ & $\mathrm{P}<0.05$ \\
\hline Triglycerides( mg/dL) & $148.11 \pm 16.57$ & $144.74 \pm 17.13$ & $\mathrm{P}<0.05$ \\
\hline HBA1c (\%) & $8.61 \pm 1.92$ & $8.21 \pm 1.75$ & $\mathrm{P}<0.05$ \\
\hline Glucose (mmol/L) & $5.44 \pm 0.98$ & $5.26 \pm 0.87$ & $\mathrm{P}<0.05$ \\
\hline Insulin (pmol/L) & $19.65 \pm 5.10$ & $18.37 \pm 4.88$ & $\mathrm{P}<0.05$ \\
\hline
\end{tabular}


Table 2: Mean value and significance of MDA, GSH, GPX, SOD, QUICKI and HOMA-IR in group (A) before and at the end of the study. MDA: Malondialdehyde; GSH: Glutathione; GPX: Glutathione Peroxidase; SOD: Superoxide Dismutase; QUICKI: The Quantitative Insulin-Sensitivity Check Index; HOMA-IR: Homeostasis Model Assessment-Insulin Resistance Index; $\left({ }^{*}\right)$ indicates a significant difference, $\mathrm{P}<0.05$.

\begin{tabular}{|c|c|c|c|c|}
\hline & \multicolumn{2}{|c|}{ Mean+SD } & \multirow{2}{*}{ T-value } & \multirow{2}{*}{ Significance } \\
\hline & Pre & Post & & \\
\hline $\mathrm{MDA}(\mathrm{nM} / \mathrm{mL})$ & $0.30 \pm 0.08$ & $0.17 \pm 0.05^{*}$ & 7.24 & $\mathrm{P}<0.05$ \\
\hline GSH (nM/mL) & $3.45 \pm 0.74$ & $4.51 \pm 0.95^{*}$ & 6.83 & $\mathrm{P}<0.05$ \\
\hline GPX (UI/mL) & $2.86 \pm 0.42$ & $3.62 \pm 0.57^{*}$ & 6.92 & $\mathrm{P}<0.05$ \\
\hline SOD (UI/mL) & $118.25 \pm 17.63$ & $98.85 \pm 12.13^{*}$ & 7.43 & $\mathrm{P}<0.05$ \\
\hline QUICKI & $0.119 \pm 0.017$ & $0.155 \pm 0.024^{*}$ & 6.85 & $\mathrm{P}<0.05$ \\
\hline HOMA-IR & $5.17 \pm 0.95$ & $3.95 \pm 0.67^{*}$ & 6.27 & $\mathrm{P}<0.05$ \\
\hline
\end{tabular}

Table 3: Mean value and significance of MDA, GSH, GPX, SOD, QUICKI and HOMA-IR in group (B) before and at the end of the study. MDA: Malondialdehyde; GSH: Glutathione; GPX: Glutathione Peroxidase; SOD: Superoxide Dismutase; QUICKI: The Quantitative Insulin-Sensitivity Check Index; HOMA-IR: Homeostasis Model Assessment-Insulin Resistance Index; $\left({ }^{*}\right)$ indicates a significant difference, $\mathrm{P}<0.05$.

\begin{tabular}{|c|c|c|c|c|}
\hline \multirow{2}{*}{} & \multicolumn{2}{|c|}{ Mean+SD } & \multirow{2}{*}{ T-value } & \multirow{2}{*}{ Significance } \\
\cline { 2 - 5 } & Pre & Post & 3.67 & P $<0.05$ \\
\hline MDA (nM/mL) & $0.34 \pm 0.07$ & $0.25 \pm 0.06$ & 3.45 & P $<0.05$ \\
\hline GSH $(\mathrm{nM} / \mathrm{mL})$ & $3.21 \pm 0.68$ & $3.84 \pm 0.72$ & 3.71 & $\mathrm{P}<0.05$ \\
\hline GPX (UI/mL) & $2.95 \pm 0.47$ & $108.45 \pm 13.44$ & 4.52 & $\mathrm{P}<0.05$ \\
\hline SOD (UI/mL) & $121.34 \pm 18.12$ & $0.134 \pm 0.023$ & 3.37 & $\mathrm{P}<0.05$ \\
\hline QUICKI & $0.120 \pm 0.019$ & $4.32 \pm 0.74$ & 3.54 & $\mathrm{P}<0.05$ \\
\hline HOMA-IR & $5.31 \pm 0.96^{*}$ & & & \\
\hline
\end{tabular}

Table 4: Mean value and significance of MDA, GSH, GPX, SOD, QUICKI and HOMA-IR in group (A) and group (B) at the end of the study. MDA: Malondialdehyde; GSH: Glutathione; GPX: Glutathione Peroxidase; SOD: Superoxide Dismutase; QUICKI: The Quantitative Insulin-Sensitivity Check Index; HOMA-IR: Homeostasis Model Assessment-Insulin Resistance Index; $\left(^{*}\right)$ indicates a significant difference, $\mathrm{P}<0.05$.

\begin{tabular}{|c|c|c|c|c|}
\hline \multirow{2}{*}{} & \multicolumn{2}{|c|}{ Mean+SD } & \multirow{2}{*}{ T-value } & \multirow{2}{*}{ Significance } \\
\cline { 2 - 5 } & Group (A) & Group (B) & 3.42 & P $<0.05$ \\
\hline MDA (nM/mL) & $0.17 \pm 0.05^{*}$ & $0.25 \pm 0.06$ & 3.61 & $P<0.05$ \\
\hline GSH (nM/mL) & $4.51 \pm 0.95^{*}$ & $3.84 \pm 0.72$ & 3.55 & $P<0.05$ \\
\hline GPX (UI/mL) & $3.62 \pm 0.57^{*}$ & $3.36 \pm 0.53$ & 3.91 & $P<0.05$ \\
\hline SOD (UI/mL) & $98.85 \pm 12.13^{*}$ & $108.45 \pm 13.44$ & 3.63 & $P<0.05$ \\
\hline QUICKI & $0.155 \pm 0.024^{*}$ & $0.134 \pm 0.023$ & 3.81 & $P<0.05$ \\
\hline HOMA-IR & $3.95 \pm 0.67^{*}$ & $4.32 \pm 0.74$ & & \\
\hline
\end{tabular}

\section{Discussion}

Oxidative stress is important in pathogenesis of diabetes complications [31,32]. The target of this study was compare response of insulin resistance and oxidative stress to aerobic versus resisted exercise training in T2DM patients. Concerning insulin resistance, both aerobic exercise and resisted exercise training significantly improved insulin resistance, these results agreed with Bacchi et al. stated that 4 months of aerobic and resistance exercises improved insulin sensitivity in T2DM with nonalcoholic fatty liver [33]. However, Angelico et al. [34] reported that up to $10 \%$ weight loss of patients with metabolic syndrome modulated insulin resistance [34]. Concerning oxidative stress, our results proved that both aerobic and resistance exercises mean values of MDA, SOD and HOMA-IR were significantly decreased, while the mean values of GSH, GPx and QUICKI were significantly increased in T2DM patients. These results agreed with previous studies that stated that 6 months of aerobic exercise increased GSH in T2DM individuals $[35,36]$. However, another study reported that 24 
weeks of resistance exercise ameliorated oxidative stress in obese individuals [37]. In addition, Oliveira et al. [38] confirmed that 4 months of aerobic exercise improved oxidative stress markers among T2DM subjects [38]. However, Vinetti et al. [39] found that 12 months of combined aerobic, resistance and flexibility training modulated oxidative stress among T2DM patients [39]. While Farinha et al. [40] mentioned that 3 months of treadmill exercise improved oxidative stress in women with metabolic syndrome [40]. Similarly, Nojima et al. [41] stated that 12 months of aerobic exercise improved metabolic control and oxidative stress markers among T2DM patients [41]. Moreover, Gordon et al. [42] proved that 3 months of Hatha yoga exercise improved glucose control, blood lipid profile and oxidative stress markers among T2DM patients [42].

The possible mechanisms for modulating oxidative stress following exercise training may include improvement in glucose control [43-46], also improved insulin sensitivity in target tissues is the second possible mechanism for reducing oxidative stress by aerobic and resistance exercise training $[47,48]$. The effects of aerobic versus resistance exercise to activate anti-aging genes that regulate insulin resistance and metabolic control is of specific interest to Type 2 diabetes. The anti-aging gene Sirtuin 1 (oxidative stress) is activated by exercise and calorie restriction with increased Sirtuin 1 levels in the blood plasma. Plasma sirtuin 1 levels have been shown to be reduced in NAFLD, obesity, diabetes and other chronic diseases. Aerobic and resistance exercise that maintain metabolic control is possibly linked to activation of Sirtuin 1 and the reversal of liver steatosis/early NAFLD [49-51].

\section{Conclusion}

Aerobic exercise is superior to resistance exercise in modulating insulin resistance and oxidative stress in type 2 diabetes patients.

\section{Acknowledgment}

This project was funded by the Deanship of Scientific Research (DSR), King Abdulaziz University, Jeddah, under grant no. (G-5-29040). The authors, therefore, acknowledge with thanks DSR technical and financial support.

\section{References}

1. (2011) IDF Diabetes Atlas. http://www.Idf.Org/diabetesatlas/5e/theglobal-burden.

2. American Diabetes Association (2010) Diagnosis and classification of diabetes mellitus. Diabetes Care 33(1): S62-S69.

3. Dandona P, Mohanty P, Chaudhuri A, Garg R, Aljada A (2005) Insulin infusion in acute illness. The Journal of Clinical Investigation 115(8): 2069-2072.

4. Monnier L, Mas E, Ginet C, Michel F, Villon L, et al. (2006) Activation of oxidative stress by acute glucose fluctuations compared with sustained chronic hyperglycemia in patients with type 2 diabetes. Journal of the American Medical Association 295(14): 1681-1687.

5. Paravicini TM, Touyz RM (2008) NADPH oxidases, reactive oxygen species, and hypertension: clinical implications and therapeutic possibilities. Diabetes Care 31(2): S170-S180.
6. Ceriello A, Motz E (2004) Is oxidative stress the pathogenic mechanism underlying insulin resistance, diabetes, and cardiovascular disease? The common soil hypothesis revisited. Arterioscler Thromb Vasc Biol 24(5): 816-823.

7. Robertson RP, Harmon J, Tran PO, Tanaka Y, Takahashi H (2003) Glucose toxicity in b-cells: type 2 diabetes, good radicals gone bad, and the glutathione connection. Diabetes 52(3): 581-587.

8. Matough FA, Budin SB, Hamid ZA, Alwahaibi N, Mohamed J (2012) The role of oxidative stress and antioxidants in diabetes complications. Sultan Qaboos Univ J 12(1): 5-18.

9. Pan HZ, Zhang L, Guo MY, Sui H, Li H, et al. (2010) The oxidative stress status in diabetes mellitus and diabetes nephropathy. Acta Diabetol 47(1): 71-76.

10. Odum EP, Ejilemele AA, Wakwe VC (2012) Antioxidant status of type 2 diabetic patients in Port Harcourt, Nigeria. Niger J Clin Pract 15(1): 5558.

11. Shi YC, Pan TM (2012) Red mold, diabetes, and oxidative stress: A review. Appl Microbiol Biotechnol 94(1): 47-55.

12. Lima V, Sampaio F, Bezerra D (2011) Parameters of glycemic control and their relationship with zinc concentrations in blood and with superoxide dismutase enzyme activity in type 2 diabetes patients. Arq Bras Endocrinol Metab 55(9): 701-707.

13. Likidlilid A, Patchanans N, Peerapatdit T, Sriratanasathavorn C (2010) Lipid peroxidation and antioxidant enzyme activities in erythrocytes of type 2 diabetes patients. J Med Assoc Thai 93(6): 682-693.

14. Lindstrom J, Louheranta A, Mannelin M, Rastas M, Salminen V, et al. (2003) The finnish diabetes prevention study (DPS): lifestyle intervention and 3- year results on diet and physical activity. Diabetes Care 26(12): 3230-3236.

15. Kodama S, Tanaka S, Saito K, Shu M, Sone Y, et al. (2007) Effect of aerobic exercise training on serum levels of high-density lipoprotein cholesterol: A meta-analysis. Archives of Internal Medicine 167(10): 999-1008.

16. Saito T, Watanabe M, Nishida J, Izumi T, Omura M, et al. (2011) Lifestyle modification and prevention of type 2 diabetes in overweight Japanese with impaired fasting glucose levels: A randomized controlled trial. Archives of Internal Medicine 171(15): 1352-1360.

17. Lindstrom J, Ilanne Parikka P, Peltonen M, Aunola S, Eriksson JG, et al. (2006) Sustained reduction in the incidence of type 2 diabetes by lifestyle intervention: follow-up of the finnish diabetes prevention study. The Lancet 368(9548): 1673-1679.

18. Bassuk SS, Manson JE (2005) Epidemiological evidence for the role of physical activity in reducing risk of type 2 diabetes and cardiovascular disease. Journal of Applied Physiology 99(3): 1193-1204.

19. Ahmadi N, Eshaghian S, Huizenga R, Sosnin K, Ebrahimi R, et al. (2011) Effects of intense exercise and moderate caloric restriction on cardiovascular risk factors and inflammation. American Journal of Medicine 124(10): 978-982.

20. Slentz CA, Tanner CJ, Bateman LA, Durheim MT, Huffman KM, et al. (2009) Effects of exercise training intensity on pancreatic $\beta$-cell function. Diabetes Care 32(10): 1807-1811.

21. Belotto MF, Magdalon J, Rodrigues HG, Vinolo MAR, Curi R, et al. (2010) Moderate exercise improves leucocyte function and decreases inflammation in diabetes. Clinical and Experimental Immunology 162(2): 237-243

22. Bjork L, Jenkins NT, Witkowski S, Hagberg JM (2012) Nitro-oxidative stress biomarkers in active and inactive men. International Journal of Sports Medicine 33(4): 279-284.

23. American Diabetes Association (2010) Diagnosis and classification of diabetes mellitus. Diabetes Care 33(Suppl 1): S62-S69. 
24. Matthews DR, Hosker JP, Rudenski AS, Naylor BA, Treacher DF, et al. (1985) Homeostasis model assessment: Insulin resistance and beta cell function from plasma FBS and insulin concentrations in man. Diabetologia 28(7): 412-419.

25. Katz A, Nambi SS, Mather K, Baron DA, Follman DA, et al. (2000) Quantitative insulin sensitivity check index: A simple, accurate method for assessing insulin sensitivity in humans. J Clin Endocrinol Metab 85(7): 2402-2410.

26. Esterbauer H, Gebicki J, Puhl H, Jürgens G (1992) The role of lipid peroxidation and antioxidants in oxidative modification of LDL. Free Radic Biol Med 13(4): 341-390.

27. Weckbecker G, Cory JG (1988) Ribonucleotide reductase activity and growth of glutathione-depleted mouse leukemia L 1210 cells in vitro. Cancer Lett 40(3): 257-264.

28. Masnini M (1988) Determination of superoxide dismutase activity with an electrochemical oxygen probe. Analyt Chim Acta 211: 195-204.

29. Deibert P, Konig D, Vitolins MZ, Landmann U, Frey I, et al. (2007) Effect of a weight loss intervention on anthropometric measures and metabolic risk factors in pre-versus postmenopausal women. J Nutr 6: 31.

30. Hagey AR, Warren MP (2008) Role of exercise and nutrition in menopause. Clin Obstet Gynecol 51(3): 627-641.

31. Ceriello A, Esposito K, Piconi L, Ihnat MA, Thorpe JE, et al. (2008) Oscillating glucose is more deleterious to endothelial function and oxidative stress than mean glucose in normal and type 2 diabetic patients. Diabetes 57(5): 1349-1354.

32. Fridlyand LE, Philipson LH (2006) Reactive species and early manifestation of insulin resistance in type 2 diabetes. Diabetes, Obesity and Metabolism 8(2): 136-145.

33. Bacchi E, Negri C, Targher G, Faccioli N, Lanza M, et al. (2013) Both resistance training and aerobic training reduce hepatic fat content in type 2 diabetic subjects with nonalcoholic fatty liver disease (the RAED2 randomized trial). Hepatology 58(4): 1287-1295.

34. Angelico F, Loffredo L, Pignatelli P, Augelletti T, Carnevale R, et al. (2012) Weight loss is associated with improved endothelial dysfunction via NOX2-generated oxidative stress downregulation in patients with the metabolic syndrome. Intern Emerg Med 7(3): 219-227.

35. Lazarevic G, Antic S, Cvetkovic T, Vlahovic P, Tasic I, et al. (2006) A physical activity programme and its effects on insulin resistance and oxidative defense in obese male patients with type 2 diabetes mellitus. Diabetes and Metabolism 32(6): 583-590.

36. Rector RS, Warner SO, Liu Y, Hinton PS, Sun GY, et al. (2007) Exercise and diet induced weight loss improves measures of oxidative stress and insulin sensitivity in adults with characteristics of the metabolic syndrome. American Journal of Physiology 293(2): E500-E506.

37. Vincent HK, Bourguignon C, Vincent KR (2006) Resistance training lowers exercise-induced oxidative stress and homocysteine levels in overweight and obese older adults. Obesity 14(11): 1921-1930.
38. Oliveira VN, Bessa A, Jorge ML, Silva Oliveira RJ, de Mello MT, et al. (2012) The effect of different training programs on antioxidant status, oxidative stress, and metabolic control in type 2 diabetes. Applied Physiology, Nutrition, and Metabolism 37(2): 334-344.

39. Vinetti G, Mozzini C, Desenzani P, Boni E, Bulla L, et al. (2015) Supervised exercise training reduces oxidative stress and cardiometabolic risk in adults with type 2 diabetes: A randomized controlled trial. Sci Rep 5: 9238.

40. Farinha JB, Steckling FM, Stefanello ST, Cardoso MS, Nunes LS, et al. (2015) Response of oxidative stress and inflammatory biomarkers to a 12 -week aerobic exercise training in women with metabolic syndrome. Sports Med Open 1(1): 19.

41. Nojima H, Watanabe H, Yamane K, Kitahara Y, Sekikawa K, et al. (2008) Effect of aerobic exercise training on oxidative stress in patients with type 2 diabetes mellitus. Metabolism 57(2): 170-176.

42. Gordon L, Morrison E, McGrowder D, Young R, Fraser Y, et al. (2008) Effect exercise therapy on lipid profile and oxidative stress indicators in patients with type 2 diabetes. BMC Complement Altern Med 8: 21.

43. Vanninen E, Uusitupa M, Siitonen O, Laitinen J, Lansimies E (1992) Habitual physical activity, aerobic capacity and metabolic control in patients with newly-diagnosed type 2 (non-insulin-dependent) diabetes mellitus: Effect of 1-year diet and exercise intervention. Diabetologia 35(4): 340-346.

44. Devlin JT, Hirshman M, Horton ED, Horton ES (1987) Enhanced peripheral and splanchnic insulin sensitivity in NIDDM men after single bout of exercise. Diabetes 36(4): 434-439.

45. Jay D, Hitomi H, Griendling KK (2006) Oxidative stress and diabetic cardiovascular complications. Free Radic Biol Med 40(2): 183-192.

46. Chugh SN, Dhawan R, Kishore K, Sharma A, Chugh K (2001) Glibenclamide vs gliclazide in reducing oxidative stress in patients of noninsulin dependent diabetes mellitus-a double blind randomized study. J Assoc Physicians India 49: 803-807.

47. Elosua R, Molina L, Fito M, Arquer A, Sanchez Quesada JL, et al. (2003) Response of oxidative stress biomarkers to a 16-week aerobic physical activity program, and to acute physical activity, in healthy young men and women. Atherosclerosis 167(2): 327-334.

48. Urakawa H, Katsuki A, Sumida Y, Gabazza EC, Murashima S, et al. (2003) Oxidative stress is associated with adiposity and insulin resistance in men. J Clin Endocrinol Metab 88(10): 4673-4676.

49. Martins IJ (2016) Anti-aging genes improve appetite regulation and reverse cell senescence and apoptosis in global populations. Advances in Aging Research 5(1): 9-26.

50. Martins IJ, Barca AMC (2016) Diet and nutrition reverse type 3 diabetes and accelerated aging linked to global chronic diseases. J Diab Res Ther $2(2)$.

51. Martins IJ (2018) Insulin therapy and autoimmune disease with relevance to nonalcoholic fatty liver disease. Intech Open.

For possible submissions Click below: 